\title{
A Report on the Breast Development of Healthy Females of the Right Age in Different Regions
}

\author{
Guosheng Su1, Zhongru Lin², Lianhua Pan1, Rongwei Liang3, Binlin Bi, \\ Xiaolu Luo ${ }^{1^{*}}$, Zhaoju Fang², Ju Zhao ${ }^{2}$ \\ ${ }^{1}$ The Fourth People's Hospital, Nanning, China \\ ${ }^{2}$ People's Hospital, Guangnan County, Yunnan, China \\ ${ }^{3}$ Maternal and Child Health Care Hospital, Qinzhou, China \\ ${ }^{4}$ People's Hospital, Wenshan County, Yunnan, China \\ Email: ${ }^{*}$ luxiaolu2007@126.com
}

Received 30 June 2014; revised 25 July 2014; accepted 21 August 2014

Copyright (C) 2014 by authors and Scientific Research Publishing Inc.

This work is licensed under the Creative Commons Attribution International License (CC BY).

http://creativecommons.org/licenses/by/4.0/

(c) (i) Open Access

\begin{abstract}
Objective: To observe the state of breast development of the healthy females of the right age in different regions. Methods: We randomly chose 1540 of 18 - 25 years old unmarried or married healthy females of the right age from both Guangxi and Yunnan provinces separately for regular checkups. Also we took notes on these females' height and chest circumference and other indexes. According to the perfect chest circumference of Chinese females in relation to height, namely this relational expression - Standard Circumference $=$ Height $\times 0.53$, we evaluated the basic state of breast development of females from the two areas and then presented related research conclusions. Results: After the statistical analyses on every index of $\mathbf{1 5 4 0}$ cases of healthy females of the right age from the two areas each, we found that the breast development of healthy women of the right age in Yunnan is more perfect than that of Guangxi, and in comparison to every index, there is a remarkable difference, and that is, $P<0.01$. Conclusions: The state of breast development of healthy females of the right age is different in different areas. Some breasts are especially big; some are a little bit smaller; some are proper and some are relatively flat; also some breasts are strong while some are pendulous. In a word, there are some differences. These differences exist not only in China but also in every part of the world. The female whose chest circumference tends to be more close to the perfect is more likely to be more confident and more active, and also her life is full of sensibility and charm.
\end{abstract}

\section{Keywords}

Area, Healthy, of the Right Age, Females, Breast, Development

\footnotetext{
"Corresponding author.
}

How to cite this paper: Su, G.S., Lin, Z.R., Pan, L.H., Liang, R.W., Bi, B.L., Luo, X.L., Fang, Z.J. and Zhao, J. (2014) A Report on the Breast Development of Healthy Females of the Right Age in Different Regions. Open Journal of Obstetrics and Gynecology, 4, 782-786. http://dx.doi.org/10.4236/ojog.2014.413108 


\section{Introduction}

The state of the development of healthy females of the right age varies with the difference of regions and customs. With the difference of the public towards aesthetic standards, people have different requirements and desires toward the development of the healthy females of the right age [1]-[3]. If the breast development of females is more perfect, it will help those females live confidently and be full of passion towards life. Furthermore, nowadays, there is more and more attention paid to the breast development of females. Therefore, our report can fill the gaps in the study of the breast development of females. In order to know the development of healthy females of the right age in different regions, the researchers tried all means and got contacts from all; from 1st May 2012 to 18th January 2013, we got the consent of each subject, and at the same time we informed China women's federation that we did test research for 10 months and 18 days without violating the social ethic, and did not disclose personal privacy or violate the provisions of laws, and we randomly chose 1540 of 18 - 25 years old young female for test investigation during the test of healthy females of the right age from Guangxi and Yunnan. Our hard work paid off. The followings are the results of our research.

\section{Materials and Methods}

\subsection{Objects of Study}

During 1st May 2012 and 18th January 2013, we chose the objects from People’s Hospital, Guangnan County, Wenshan State, Yunnan Province, China, People’s Hospital, Wenshan County, Wenshan State, Yunnan Province, China, Maternal and Child Health Care Hospital, Qinzhou City, Guangxi Province, China etc. Then we randomly chose 1540 of 18 - 25 years old unmarried or married healthy females of the right age from both Guangxi and Yunnan provinces separately for regular checkups. Before the checkups, we have made sure that the breasts of the research objects develop normally, that the breasts are never through artificial implants and the objects are unmarried females or married but haven't give birth to children. What should be mentioned is that the number of females who do regular checkups in the hospitals we chose is between 15 thousands and 30 thousands, which could provide enough people for this study. Moreover, before this study, we have done a minimum sample size calculation process. In the study, we randomly chose 100 healthy females of the right age for checkups. We found that, the breast development of Yunnan is more perfect than that of Guangxi. Therefore, we decided to do a maximum sample size calculation process.

\subsection{Research Methods}

Measure each lady's height and chest circumference with a soft plastic metric scale. And the chest measurement includes three sets of data: first, take seats, and make two hips close up, then measure the length to two alar as chest circumference $1(\mathrm{~L} 1)$, for measure the span of breast size. When measuring, if the measure values are odd numbers, then we take the maximal even number adjacent, such as $34 \mathrm{~cm}, 36 \mathrm{~cm}$, and $38 \mathrm{~cm}$ etc. Then the chest circumference $1(\mathrm{~L} 1)$ minus $1 \mathrm{~cm}$ is the span of breast $(\mathrm{K})$. Second, through the nipple, the horizontal measurement from the place of the plumpest breast to two alar, then the length is chest circumference 2(L2). Then we take the difference between L2 and L1 to determine the breast of the crown (T). Third, through the nipple, the horizontal measurement from the place of the plumpest breast to Oster covering the length of dorsal is chest circumference 3(L3). And the ratio L3 to height (H) is used to measure the size of the chest [3].

\subsection{Judgment}

The breast whose span is normally shorter than $34 \mathrm{~cm}$ is especially small. And the standard one is $36 \mathrm{~cm}$. The one longer than $38 \mathrm{~cm}$ is especially big. The convexity of chest is expressed with A, B, C and D. If the difference between L2 and L1 is $6-11 \mathrm{~cm}$, and it is A. The difference is $11-13.5 \mathrm{~cm}$, and it is B. The difference is $13.5-16 \mathrm{~cm}$ and it is C. The difference is $16-18 \mathrm{~cm}$ and it is D. The one smaller than B is especially small, and $\mathrm{C}$ is standard and the one bigger than D is especially big. Also, the ratio of $\Phi<0.49$ between L3 and H is defined to be especially small, and one with the ration of $\varphi=0.53$ is the standard one, and also the one with the ratio of $0.53<\varphi<0.6$ is beautiful and the one with the ratio of $\varphi>0.6$ is especially big. And that is to say, as for a $1.60 \mathrm{~m}$ high mature female, her standard chest circumference should be $84.8 \mathrm{~cm}$, and also as for a $1.70 \mathrm{~m}$ high mature female, her standard chest circumference should be $90.1 \mathrm{~cm}$ [1] [2]. 


\subsection{Statistical Treatment}

Using software of SPSS17.0 for statistical analysis, showing the measurement data with \pm , testing the comparison of the measuring unit by $\mathrm{t}$, testing the comparison of count data by matching chi square and with the $\mathrm{P}<$ 0.05 for the difference was statistically significant.

\section{Results}

Between the 3080 of females in the right age, the breast development of females in Yunnan is more perfect than that of Guangxi. There is clear difference between $\mathrm{N}, \mathrm{K}, \mathrm{T}, \varphi(\mathrm{P}<0.01)$. The breast span $(\mathrm{K})$ of females in the right age in Yunnan, China is $\leq 0.49 \mathrm{~cm}$, while that in Guangxi China is $35.27 \pm 0.33$. Comparing this result, $\mathrm{t}=$ 18.9852, $\mathrm{P}=0.00136$. the breast of females' crown $(\mathrm{T})$ in Yunnan, China is $15.67 \pm 0.26 \mathrm{~cm}$, while in Guangxi is $13.62 \pm 0.28 \mathrm{~cm}$, comparing this result, $\mathrm{t}=35.42, \mathrm{P}=0.000728$. In addition, according to the ratio of ladies height and chest circumference $(\varphi)$, the $\varphi$ in Yunnan is $0.58 \pm 0.05$ while in Guangxi is $0.51 \pm 0.02$, the result is $t$ $=6.83, \mathrm{P}=0.00378$. The results of the condition of breast development of the right age healthy females in Yunnan and Guangxi province China as Table 1.

\section{Discussion}

Breast is one specific secondary characteristic that a female has, and it is the characteristic of human and mammal and it is also an ectoderm organ. Whether the breast development of females is good or not reflects the shape and beauty of the female body. If the breast is well developed, the female will have a perfect plump chest and healthy beautiful body shape which makes females be confident and positive toward life. On the contrary, if it is not well developed, it not only greatly influences the image and sense of females but also brings a lot puzzles and troubles to females. According to the research from experts [3], the breast of adult females are located among the 2nd - the 6th rib of the front chest and on the edge next to the sternum and on the outer edge of the axillary front and also are located on the 1/3 surface of the stratus anterior, but sometimes the cover of breast tissue is probably larger. And sometimes the tender part of breast tissue extends upward clavicle and downward anterior rectus sheath and is located inside the middle route of the sternum and outside the latissimus dorsi front. And as to the 95\% upper parts of the breast there is a long narrow breast tissue which extends to the armpit and that is called the axillary tail of mammary gland [4] [5]. Also, the shape of breast varies with the factors like race, heredity, age, motion, wear of bra, nutriture, fat or thin, the fat content in females' breast, breed and lactation, etc. There are many differences on the shape of breast, for example, the estrogen in young females' bodies flourishes a lot, or the breast tissue is sensitive to the estrogen and the breast is becoming bigger day by day and even the corset cannot control it. Thus some breasts are big and some develop very slowly and even some are very small which are like the breast of males or one side of the breast doesn't develop but become malformation.

In this study, the breast development of Yunnan is more perfect than that of Guangxi, and according to the results of the survey analyses, the possible reasons about the causes are the following factors. Firstly, Yunnan locates in the high altitude area, and there the sunshine is strong and ultraviolet ray irradiate into the human body and excites the chest cell and then accelerate the growth of chest cell and also accelerate the development of breast .Secondly, the eating habits between Yunnan and Guangxi are different, and the people in Yunnan tend to eat spicy food and dog meat and other food of high protein and high fat. Hot peppers excite the growth of breast cell in a way, and dog meat can gain the fat in the breast and then it makes the breast develop to be bigger. But the eating habits in Guangxi are quite opposite, people there like light food and tend to keep slim. Thirdly,

Table 1. The comparison between Yunnan and Guangxi of China the right age healthy female breast development condition (X average $\pm S$ ).

\begin{tabular}{|c|c|c|c|c|}
\hline District/Comparison & $\mathrm{N}$ & $\mathrm{K}(\mathrm{cm})$ & $\mathrm{T}(\mathrm{cm})$ & $\varphi$ \\
\hline Yunnan of China & 1540 & $37.53 \pm 0.49$ & $15.67 \pm 0.26$ & $0.58 \pm 0.05$ \\
\hline Guangxi of China & 1540 & $35.27 \pm 0.33$ & $13.62 \pm 0.28$ & $0.51 \pm 0.02$ \\
\hline $\mathrm{T}$ & - & 18.9852 & 35.42 & 6.83 \\
\hline $\mathrm{P}$ & - & 0.00136 & 0.000728 & 0.00378 \\
\hline
\end{tabular}


the climate and the water for life in those two areas are different. The climate and the environment in Yunnan is great and Yunnan has the name of Green Mountains and Clear Wante; Spring All Year Around. So people there have a good mood the every part of the body develops well. As for the water for life, the trace element in the water of the two areas varies, and probably some elements in the water of Yunnan accelerate the breast develop faster. Though the climate, environment and water resource, etc. in Guangxi is better than that of Yunnan, there are also some differences between Yunnan and Guangxi. Of course, those reasons are just from some simple tests of this research and preliminary examinations, so the exact reasons are not just those above. And it is hard to make sure the breast development is related to those factors. But if we want to truly analysis the reasons, we still need to explore them further.

\section{Conclusion}

In a word, despite the reasons, the breast development of females in Yunnan is more perfect than that of Guangxi. People can accept the truth naturally because of the different life styles in different areas. Research shows that the breast development varies not only in Yunnan and Guangxi but also in different areas, different regions and different countries. The breast development varies between America and England, and it also varies between French and Brazil, and between India and Belgium. It varies among every country around the world, and the breast development is always unbalanced and different. The female whose breast is more perfect will be likely to be more confident and more active, and also her life is full of sensibility and charm. The purpose of this report is to make more people understand the difference of females' breast development in different areas. Then females can change their breast shape through various means, such as motion, massage or stimulation of the physical and chemical ways according to their aesthetic individual view. We hope our research can provide more women with more information to build their beauty, which will also cause more social and economic benefits.

\section{Acknowledgements}

We got much support and help from The Fourth People's Hospital, Nanning City, Guangxi Province, China, People's Hospital, Guangnan County, Wenshan State, Yunnan Province, China, People’s Hospital, Wenshan County, Wenshan State, Yunnan Province, China, Maternal and Child Health Care Hospital, Qinzhou City, Guangxi Province, China, China women's federation and many staff and all testees. And here we give our sincere thanks and earnest greetings to all the staff involved in this research!

\section{Statement}

What deserves to be mentioned is statement in the study, we got the consent of each subject, at the same time we informed China women's federation we did test research for 10 months and 18 days, without violating the social ethic, and not disclose personal privacy, not in violation of the provisions of laws. And the above article mentioned that people in Yunnan like eating dog meat, and this is because in some parts of Chins there people have the custom of eating dog meat and they think dog meat is the most nutritious and of high fat among all meats and here we particular announce that the dog meat they eat is from the dogs which are artificially fed.

\section{Funding}

Guangxi Nanning City Science and Technology Plan Projects of the People’s Republic of China (NO. 2011 06048C-2).

\section{References}

[1] ASPS (2011) 2000/2009/2010 National Plastic Surgery Statistics.

[2] Avsar, D.K., Ayqit, A.C., Benlie, R.E., et al. (2010) Anthropometric Breast Measurement: A Study of 385 Turkish Female Students. Aesthetic Surgery Journal, 30, 44-50. http://dx.doi.org/10.1177/1090820X09358078

[3] Chen, W.J., Li, G.S., Liu, L.P., et al. (2007) Measure the Young Unmarried Females’ Nipple Position Determination and Analysis of the Related Factors of China. Chinese Journal of Medical Aesthetics and Beauty, 13, 158.

[4] Aqbenorku, P., Agbenorku, M., Iddi, A., et al. (2011) Measurement of Breast of Young West African Females: A 
Guideline in Anatomical Landmarks for Adolescent Breast Surgery. Aesthetic Plastic Surgery, 35, 49-54. http://dx.doi.org/10.1007/s00266-010-9555-1

[5] Jiang, X.L., Cheng, C. and Zhang, C. (2011) Measure the Unmarried Young Females’ Breast of Dalian City, China. Chinese Journal of Aesthetic and Plastic Surgery, 22, 222-224. 
Scientific Research Publishing (SCIRP) is one of the largest Open Access journal publishers. It is currently publishing more than 200 open access, online, peer-reviewed journals covering a wide range of academic disciplines. SCIRP serves the worldwide academic communities and contributes to the progress and application of science with its publication.

Other selected journals from SCIRP are listed as below. Submit your manuscript to us via either submit@scirp.org or Online Submission Portal.
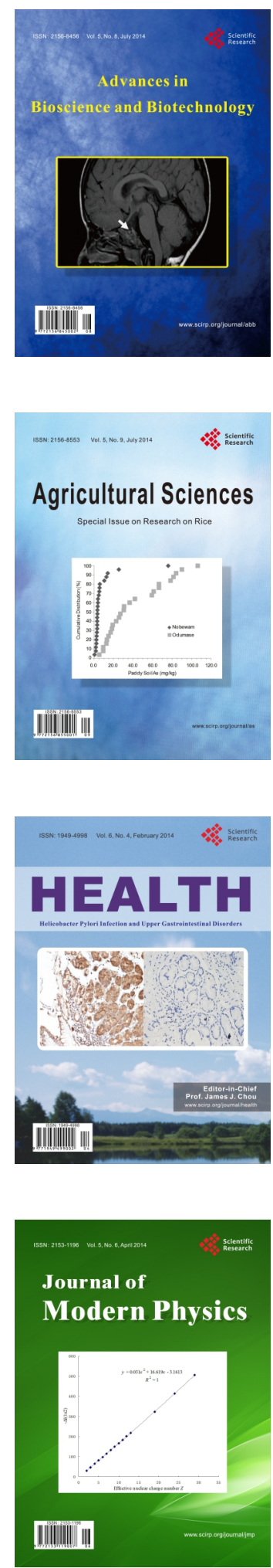
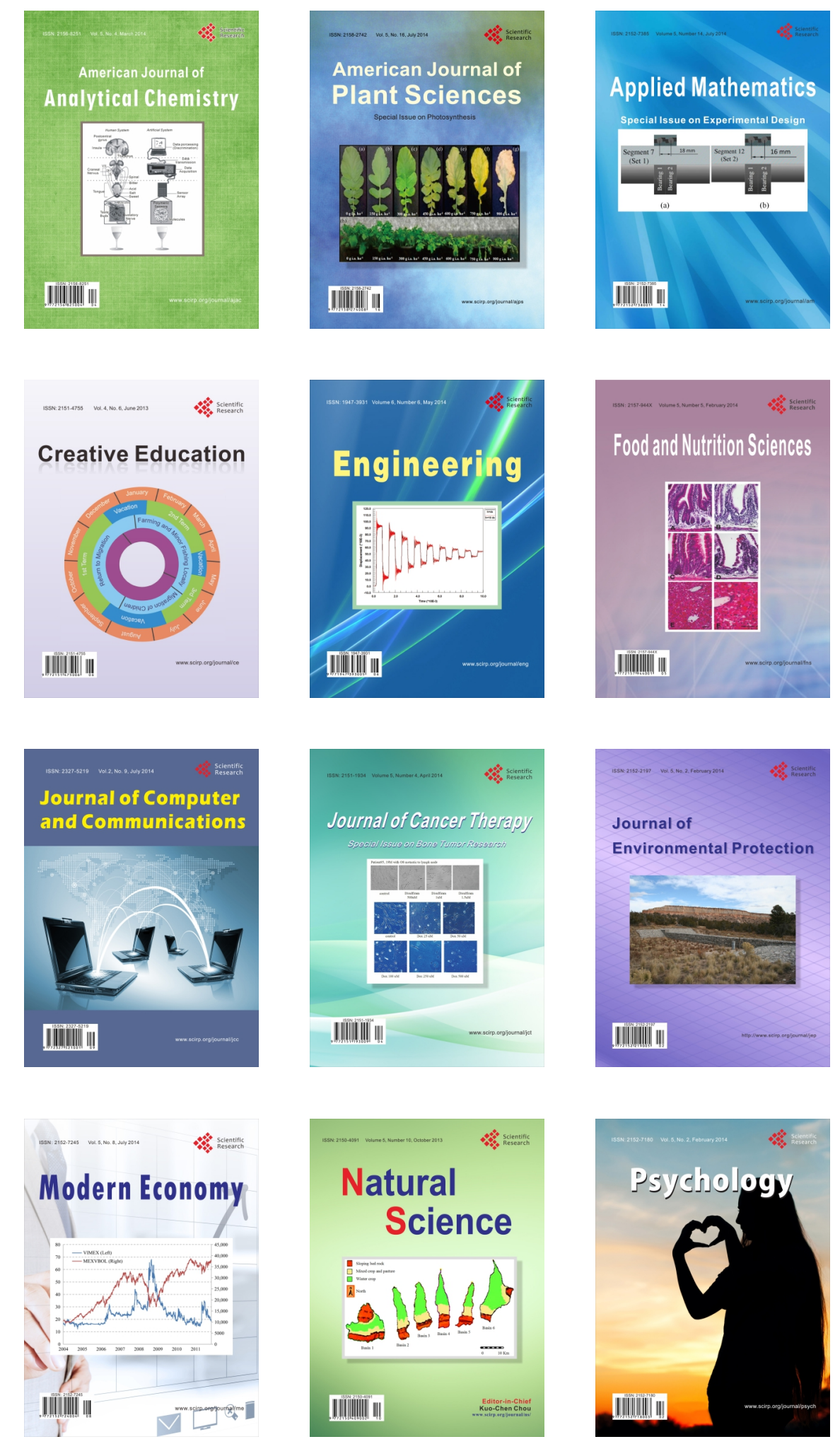